\title{
A Post-traumatic Defense Mechanism on Toni Morrison's Portrayal of Pecola in The Bluest Eye
}

\author{
Farhat Tasannum Farah
}

\author{
Assistant Professor, Department of English, American International University-Bangladesh \\ Received: 12 Oct 2021; Received in revised form: 15 Nov 2021; Accepted: 22 Nov 2021 \\ (C)2021 The Author(s). Published by TheShillonga. This is an open access article under the CC BY license \\ (https://creativecommons.org/licenses/by/4.0/)
}

\begin{abstract}
Trauma is a universal experience of human being. The intensity and characteristics of traumatic experiences vary from person to person, culture to culture; and they also depend on the other psycho-socio-cultural variables; and the defensemechanism has no particular order. In order to making points clearer and focused, this paper has been divided into three subsections. The first section is a narrative essay on trauma and post-traumatic ego defense mechanism. The second part broadly focuses on some common defense mechanism and the third section discusses on a particular defense mechanism, dissociating reality and associates it with the idea of insanity. As a whole, this research paper deals with Post-traumatic Defense Mechanism, focuses on the character of Pecola as a mother in The Bluest Eye by Toni Morrison that reads a deconstructed idea of "insanity" to interpret the character.
\end{abstract}

Keywords - trauma, PTSD, defense mechanism, insanity, dissociating reality.

The process of giving birth to a human being is a traumatic experience both for the mother and the infant; this is a physical stress for them. Referring to this traumatic experience, John L. Vogel, in his book, Thinking about Psychology, says, "Being born must have been quite an experience. We moved from a dark, warm, moist place into the glaring and busting world which must have required major adjustments. We've been making adjustments to a changing environment ever since." (Vogel: 388). This simple confession bears a deeper meaning that being alive involves some degree of stress; and this stress is the mother of Trauma. A traumatic event or trauma refers to the experience which is severely physically or psychologically painful or stressful. Extreme traumatic events may create Post-Traumatic Stress Disorder (PTSD); but human beings are born as hedonistic creatures, and each have an individual ego-defense mechanism against traumatic experiences.

Though trauma is a universal human experience, the intensity and characteristics of traumatic experiences vary from person to person, culture to culture; and they also depend on other psycho-socio-cultural variables to which the defense-mechanism has no particular order. This chapter briefly discusses trauma, post-traumatic stress disorder, several common ego defense mechanisms, and dissociating reality as an ego-defense mechanism. In this chapter I have also associated "insanity" with "dissociation of reality". In order to make my points clearer and more focused, I have divided this chapter into three subsections. The first section is a narrative essay on trauma and posttraumatic ego defense mechanism. The second part broadly focuses on some common defense mechanism and the third section discusses a particular defense mechanism, dissociating reality and associates it with the idea of insanity.

\section{Trauma}

No matter how resourceful people may be in coping with problems, the circumstances of life inevitably involve stress. Long term, intensely stressful situations may create severe trauma. In order to understand what trauma does to humans, we must first understand what trauma is. Lenore Terr, a child psychiatrist, writes, "psychic trauma occurs when a sudden, unexpected, overwhelming intense emotional blow or a series of blows assaults the person from outside. Traumatic events are external, but they quickly become incorporated into the mind" (1990). Van der Kolk makes a similar point about the complicated nature of trauma saying, "Traumatization 
occurs when both internal and external resources are inadequate to cope with external threat" (1989). Both clinicians make the point that it is not the trauma itself that does the damage. It is how the individual's mind and body react in its own unique way to the traumatic experience in combination with how one's social group effects that response.

Trauma is "any kind of event, which is physically or mentally severely uncomfortable or stressful for the subject, can be termed as trauma." So, it can be said that trauma originates from highly stressful events. A major source of stress is conflict between two opposite motives. When two motives conflict, the result of one leads to stress. Sometimes conflict arises between a motive and a person's internal standards. For example, one's desire of having an intimate relationship with an engaged person may conflict with the sense of morality and consequently the desire may be repressed by the sense of morality causing stress. These types of conflicts create stresses which can be easily coped with. But, there are other forms of stress which may turn into severe trauma for the subject. Sexual abuse is such an event that may cause the victim to become severely traumatized. Sexual abuse is a traumatic experience for the victim as it makes him/her feel vulnerable. If the victim is abused by a father figure, the trauma is more intensified as it is related to the idea of incest. In most of the cases traumatized victims are seen to reveal painful stories of sexual abuse in their lives and these abusive relationships create anxiety or trauma within them.

So, it can be said that trauma is related to abuse. If the victim is abused (physically, sexually, or emotionally) s/he would be traumatized by these experiences and this trauma may lead the victim to destructive psychiatric illnesses.

A child's relationship with its mother is an important factor in case of its personality development and minor failure by the mother is seen as a stimulus to infantile development while a major failure as a catastrophe (Curnow 2014). So, if the subject has a problematic relationship with his or her mother in its infancy, it may turn into a trauma for him or her later in life. Referring to the importance of the children's relationships with their mother, Hilgard and Atkinson says: "Mothers (of schizophrenic patients) have been found to be both overprotective and rejecting, neglectful and overly involved with their offspring, too restrictive and too permissive. (Hilgard, Atkinson, Rita 1976)

Trauma is a very uncomfortable emotion that threatens the psychological self. It cannot be tolerated for long and the victim is strongly motivated from within to do something to normalize the discomfort. The consequence of trauma may vary from person to person depending on their age, sex, and other psycho-social variables. According to Freud (1920) and later authors (e.g.: Garland, 1998), we experience trauma when there is a disruption of a protective barrier in our mind, which protects us from harmful and painful excessive stimulation. According to psychologists, a person may suffer from an instant breakdown when the protective shield is crushed by trauma, and there may be a catastrophic disruption of functioning. The victim may suffer from the fear of death, or may be threatened by total annihilation of the self. In most of the cases, the victim is shocked, confused and, most importantly, unable to take in what has occurred. After the primary reaction, s/he may act like a different person. For example, an extrovert may turn into an introvert and an introvert may turn into an extrovert. Whatever it is, in this state, psychiatrists describe people as "dissociated". In some cases the victims/survivors may attempt to return to normal functioning by seeking a rational explanation of the event. Although, in most of the cases, there is no satisfactory explanation, and the victim creates another reality to explain the incident in order to defend his/her ego. For example, a survivor of a car accident, that caused harm to others, may seek for condolence through blaming others externally ("The other driver was responsible for the accident."), or internally ("They made me feel so bad that I couldn't control myself...") that is felt to be responsible for their predicament. Freud used the term "defense mechanism" to refer to these unconscious processes that defend a person against trauma to resolve the interna/external issues they are undergoing. These mechanisms defend the ego against external threats or against internal anxiety-arousing impulses by "distorting reality" in some ways.

Defense mechanisms do not alter the objective conditions of the danger; they simply change the way a person thinks about it. Defense mechanisms differ in the extent of distortion or self-deception involved and in the source of danger they ward off. Defense mechanisms are psychological constructs made from a person's circumstances. In varying degrees, everyone uses a defense mechanism in their everyday life. Used in moderation, these defensive behaviors increase satisfaction in living and are therefore a helpful mode of adjusting. However, when these behaviors become dominant, it intensifies personality disorders. The defensive behavior no longer defends the ego. Instead it offers the ego an alternate reality. The ego therefore changes its behaviors to fit the new reality. The defensive behaviors become a "dominant mechanism" for the severely traumatized person.

\section{Post Traumatic Defense Mechanisms}


Dissociation is one of many symptoms experienced by some victims of multiple forms of childhood trauma, including physical, psychological, and sexual abuse (Myers 2002). Studies suggest that dissociation is correlated with a history of trauma. Dissociation has a high specificity and a low sensitivity to having a self-reported history of trauma. This means that dissociation is much more common among those who are traumatized. Concurrently, there are many people who have suffered from trauma but do not show dissociative symptoms (Briere 2006). These symptoms of dissociation resulting from trauma may include depersonalization, psychological numbing, disengagement, or amnesia regarding the events of the abuse.

Scientist have hypothesized that dissociation provides a temporary defense mechanism in cases of severe trauma. Nevertheless, long term use of dissociation is associated with decreased psychological functioning and adjustment.

Child abuse, in particular, especially chronic abuse starting at early ages, has been related to high levels of dissociative symptoms in clinical studies. Clinical studies have confirmed that child abuse, in particular, is related to high levels of dissociative symptoms, especially chronic abuse during childhood. Sexual abuse of a child increases the likelihood of a child having dissociative tendences. This correlated with the severity of the abuse makes for an extreme case of dissociation. A 2012 review article supports the hypothesis that trauma may affect a person's assessment of the past. The trauma forces the person to create a different reality. People who use dissociation often have a disconnected view of themselves because of this distorted reality. Time and their own self-image may not flow continuously as it does for most people. In this manner, a person who dissociates can "disconnect" from the real world and create their own version of this world effectively disconnecting from reality in order to live uncluttered by unbearable memories and feelings.

\section{Black America}

The Bluest Eye tells us the story of Pecola Breedlove, a 12-year old Black American girl of the 1930s. The lifestyle of Black people in America in the '30's has been depicted in the novel very internally, not from the point of view of the dominant white people, but from the point of view of themselves. Morrison, as a Black American, has expressed her own experiences as a character of the novel, Claudia.

What we call today's United States of America was basically a combined colony of people from Great Britain and other European countries. Black people were brought to America from Africa and the Caribbean Islands in the $17^{\text {th }}$ century as slaves. According to historians, in the early 17th century, European settlers to North America began kidnapping African slaves as a cheaper, more plentiful labor source than indentured European servants. Around 1619, a Dutch ship brought several Africans to the British colony of Jamestown, Virginia. Afterwards, slavery spread throughout the American colonies. Although historians find it impossible to give accurate numbers, some have estimated that approximately 7 million slaves were imported to North America during the 18th century, depriving the African continent of some of its healthiest and ablest men and women.

In March 1861, the Republican candidate, Abraham Lincoln, was elected as president. After that, within three months, seven southern states had seceded to form the Confederate States of America. Four more followed them after the Civil War (1861-65) began. Though Lincoln had antislavery views, the central Union war aim, at first, was not to abolish slavery, but to preserve the United States as a nation. Abolition later became a war aim due to military necessity, growing anti-slavery sentiment in the North and the self-emancipation of many African Americans who fled enslavement as Union troops swept through the South. In September 1862, Lincoln, five days after the gruesome victory by the Union at Antietam, issued a preliminary emancipation proclamation, and on January 1, 1863, he made it official that "slaves within any State, or designated part of a State...in rebellion,...shall be then, thenceforward, and forever free.

Black Americans are the later generations of those who were brought here as slaves. However, though slavery was dissolved in the $19^{\text {th }}$ century, American society did not accept Black people as their complete citizens. On the other hand, Black people had no place to go as they had been living in the New World for generations. The situation was, in no way, in favor of Black people. This gave rise to racism and classism in mainstream American society. White Americans were forced to accept Black people in new ways, but they refused to accept that Black people were entitled to the same rights.

The Bluest Eye presents a scenario of the condition of the Black American women of the 1930's. It shows us that the Black women in America were victimized because they were black, female, and poor, not only from White Americans, but also from Black men. In America, Black women face racism, sexism, and classism. These are traumatic conditions under which they live in White America. These are the social and psychological oppression that has adversely affected the lives of Black Americans in general and particularly the Black American women. The Black community had to face atrocities like racism and exploitation, irrespective of sex. However, the Black women were more oppressed physically and 
mentally and their cause of grievances was greater. Pushed to the periphery on account of their gender, a Black women's lives were full of traumatic experiences due to sexism, racism, and exploitation.

Sexism refers to the gender bias which subordinates women to men and exists in all patriarchal modes of thinking. The patriarchal and endocentric ideologies provide women secondary roles and focus on concepts of gender differences which are not natural but manmade. While the White women have been victims of these prejudices, the Black woman's position has been more vulnerable. These women had to suffer at the hands of both white and black men, fighting a battle for survival both inside and outside their homes. While the whites tortured and raped Black women, the black men developed a kind of aversion towards the women of their community, regarding them as loose characters which would prefer extra marital adventures to marital permanence. The Black women, therefore, had no protection from the men of their own community. In the Bluest Eye, we can see this in Pauline and Cholly's relationship. In the past, Cholly was forced to have intercourse with a woman by white men. This impressed upon him an inability to connect with his significant other. Not being able to emotionally connect with Pauline, Cholly grows to resent her and their children seeing them all as objects rather than his family. This leads to domestic violence against Pauline and the rape of Pecola.

In addition to this, America promoted women to be beautiful in an ornamental way. Women were not workers in the 1930's, but instead were chaste, pious and married. If we notice the Hollywood films or sitcoms, we will get introduced with the concept of "cheerleader". A cheerleader refers to the girl who is "beautiful" in an American way, and, so, is popular. These movies and sitcoms (which are actually the depiction of "Americanness") show that still the dream an average American teen-aged girl is being a "beautiful" cheerleader. On the contrary, the Black American woman was (and still is) an obsolete anti-thesis of this image- she was not ornamental because she had to work and according to the aesthetics of the country, she was not beautiful because she was not white. So, this conceptualized beauty was one of the most traumatic experiences for the Black American women. In the Bluest Eye, we can see this in Pauline Breedlove. As a child, she refuses to straighten her hair, instead keeping it natural. In America, straightened hair is the ideal. As it is easier for White women to do, Black women are constantly lagging. Pauline rejects this idea of beauty in her youth. But as she grows up watching movies, she conforms to the mainstream American idea of beauty. Furthermore, she puts this pressure on her daughter,
Pecola, to be beautiful like the White women, instead of ugly.

Another painful experience of Black Americans was/is racism which began in America when White slave masters brought the African slaves in chains and used them as laborers to work on plantation farms to fill their coffers. Very soon the Black laborers lost their identity of human beings in the White world and were reduced to just a profit-making body. The Wikipedia Free Encyclopedia defines "racism" as "beliefs, practices and institutions, which negatively discriminate against people based on their perceived or ascribed race." Sometimes the term is used to describe the belief that race is the primary determinant of human capacities, or a more general attitude that individuals should be treated differently according to their race. The basic principle of racism is that white skin brings with it cultural superiority. The White people are perceived as more intelligent and virtuous than the Black people and blackness is associated with sin, dirt and cultural inferiority. In the Bluest Eye, the community accepts these ideologies. Claudia, Frieda, and others all judge Pecola and ultimately decide she is ugly and stupid. They perceive her blackness as inferior to their own. These sentiments push Pecola to become an outcast because her own society is unaccepting of her.

In American history Black people's situation has always been connected to race, class and gender. These White ideologies have been playing the leading role in traumatizing the poor Black women. They, in fact, originated from the same set of circumstances and are motivated by economic, social and psychological forces. Gloria Wade Gyles explains this through an imagery of circles:

"There are three major circles of reality in American Society, which reflect degrees of power and powerlessness. There is a large circle in which white people, most of the men, experience influence and power. Far away from it there is a small circle, a narrow space, in which there are the black people, regardless of sex, experience, uncertainty, exploitation and powerlessness. Hidden in this second circle is a third, a small dark enclosure in which black women experience pain, illation and vulnerability. These are the distinguishing marks of black womanhood in white America." (1984: 3 - 4)

\section{Pecola's Analysis}

The reasons for why and how Pecola began seeing beyond the reality and dissociating reality are complex. In the novel, this was labeled insanity because she began talking to herself or to someone unseen by 
others. Ultimately, she believed she had gotten her desirable blue eyes which were the bluest of them all. There were many traumatic experiences that led Pecola to this dissociative reality, including her relationship with her parents and her loss of identity.

All through the novel, young, black Pecola Breedlove wants nothing more than to be loved by her parents her; all she wants is to be recognized by them; but, all she gets from them is continuous denial. Finally, poor Pecola comes to the decision that the reason she is despised and ridiculed is that she is black. In fact, the novel mentions that her skin is a lot darker than most other black people, which is the main reason that she is ignored, criticized, and ridiculed even by black people, and therefore, ugly. From early in her childhood, she has been taught that the standard of beauty is being white and having straight blond hair and blue eyes, like the 30s icon Shirley Temple. This concept of beauty makes her realize that if she had blue eyes, all the problems of her life would be solved (like the problems of Shirley's life in the movie Bright Eyes (1934) was solved as she was very much adorable). Consequently, her desire for blue eyes, her desire to be loved - in other words, her desire to look like Shirley Temple, (who, Pecola thinks, is adored by all just for her beauty) turns into an obsession (Tate, C., 1985). As discussed before, the concept of beauty in the White dominate society is an unpleasant experience for Black women. It is a major event that makes them feel inferior and, therefore, traumatized as it makes them realize that they can never attain the status that white women have and, therefore, can never be truly beautiful.

The process of dealing with this feeling is a kind of ego defense mechanism and it varies from person to person. We have seen three major female characters of the novel- Claudia, Pauline and Pecola go through this same experience, but their reactions were different. Claudia, as a rebellious character, rebels against the concept through choosing Jane Withers over Shirley Temple and expresses her hatred for the way her people adore Shirley. Claudia celebrates her existence and her individuality. On the other hand, Pauline, Pecola's mother, surrenders herself to the white ideology; she accepts the truth that she can never be beautiful. But, Pecola, unlike Claudia and Pauline, becomes obsessed with her desire of beautiful. She accepts the white ideology but denies that she can't be like them; rather, at one point, she starts believing that she will get blue eyes. As Soaphead Church, a fake monk, made her believe that her wish of having blue eyes and being loved had been granted by the God and would be fulfilled soon. The monk convinced her that God could and would change her into a beautiful girl with blue eyes. Pecola, convinced that this was possible, prayed and believed she would become different.

Ultimately, this begins during her childhood as Pecola has been rejected by her mother throughout her childhood. This denial makes her obsessed with the beauty as she sees that to her mother, the white child of her Master is more adorable than her own. Her mother, Pauline, finds haven, hope, life and meaning as a servant to the white, blond, blue-eyed, clean, rich, family to which she dedicates her love and her respect for an orderly life that poverty does not afford (McKay, 1988). Even, after being violated by Cholly, her father, Pecola did not get any support from her mother, rather she was brutally beaten up. Pauline felt guilty for not being able to rise above poverty and offer her daughter a better childhood than her own. This guilt caused her to lash out at Pecola and reject her. In addition, Pauline felt threatened after Cholly rapes Pecola. She feared being replaced and cast out by Cholly. Knowing she has no other safety net or chance of decent livelihood alone; she rejects her daughter and tries to remain in good standing with Cholly. These two emotional states is what forces Pauline to reject her own child. Ultimately, this maternal rejection is a very strong force for traumatizing a child. In fact, in Introduction to Psychology, "maternal rejection" has been mentioned as a "psychological factor" of schizophrenia (Hilgard, Atkinson, Rita 1976) which is seen later in the novel.

The nature of the mother/daughter relationship existing between Pecola and Pauline Breedlove is simply that of a provider and dependent minor. It is her coldness towards her children and her teachings of self-hatred that psychologically destroy Pecola. Pauline Breedlove plays a major role in Pecola's mental breakdown. She, as a mother, absolutely gives no mental support when Pecola was ravaged and ruined by her own father. She rather blames her and thus is a willing participant in the destruction of Pecola's self-image. Her preference for the white Fisher girl over Pecola validates Pecola's low self-esteem. In The Bluest Eye, Toni Morrison demonstrates that mothers are like role models, who as examples shape their daughters' attitudes and behaviors. But, unfortunately, Pauline's constant hatred and disgust of her daughter is actually a projection of her own insecurities and self-hatred which paves the way for Pecola to follow her lead into the path of self-destruction and disgrace.

The other traumatic experience that Pecola undergoes is the loss of her identity. Pecola was rejected not only by her family, but also by society, for her marked ugliness. This causes her to suffer through severe identity crisis all through her life. The lack of social recognition is traumatic experience in her life. The Black American people of the 
1930's were treated as sub-human and the condition of the Black female was even more dire; they were doubly oppressed through both the ideologies of racism and sexism. As a member of the Black society Pecola did not hope or expect to be accepted in White society, but she did expect to be recognized and accepted by the people in her own community.

Similarly, it is very much certain that Pauline, going to the movie theatres, was introduced to the concept of physical beauty. At first, she expected to be like the movie stars; but in a an accident she losses her front tooth, which makes her feel that she can never be beautiful like those rich, white, slim heroines with straight hair and fine clothes. This experience is the most traumatic in Pauline's life and causes inner turmoil. Pauline is so broken that she stops trying to be beautiful like the stars of the movies. As an adult woman, Pauline employs the mature defense, sublimation. As she has nothing to do with the ideology of the society, she simply changes her area of concentration. Pauline lives with the traumatic experiences in her adulthood even though the rest of her childhood was with a stable family. In spite of being crippled, Pauline, in her adulthood, is not seen to be denied by her family or by the society. The trauma she encountered, takes place in her adulthood.

However, Pecola's trauma is more intensified than her mother's. Her experiences start from early childhood, as we see after Pecola's birth when Pauline is lamenting inside that she has given birth to an ugly girl. In fact, Pecola is not given the right to address her mother as Mother or Mom; like outsiders, she calls Pauline "Mrs. Breedlove." All through her childhood, Pecola faces denial and negligence and after entering young womanhood, she is raped and impregnated by her father, Cholly. The situation turns grimmer when she is brutally tortured by her mother and consequently losses the baby. This series of traumatic experiences is overwhelming for a young girl who has never experienced love because she is not beautiful. After receiving the final denial from her mother. Pecola had no other way to survive in this sick reality without dissociating it.

Pecola's reality is too harsh to cope with. Consequently, in order to defend her ego, her subconscious chose a form of primitive defense mechanism and dissociates the reality she lives in. She creates her own reality in which she will get her blue eyes, and she can converse with her imaginary friend that understands and loves her. In doing so, Pecola uses the defense mechanism to separate herself from the rest of her world. This extreme use of a defense mechanism makes her psychologically unstable. Unfortunately, the book ends with Pecola remaining unstable and no one coming to her aid. The bleak outlook of her life is that she will continue to dissociate from the world believing she has the bluest eyes.

Toni Morrison's grim outlook on Pecola's future suggests that African Americans need to support each other. After slavery ended, many had hoped that a better future was on its way. Morrison reminds us that this better future is only possible if the mothers, fathers, sons, and daughters of this new generation build each other. This means believing that African Americans are beautiful on the inside and outside.

\section{REFERENCES}

[1] Beaulieu, Elizabeth Ann. Black Women Writers and the American Neo-Slave Narrative. Westport, Connecticut: Greenwood Press, 1999.

[2] Berger, James. "Ghosts of Liberalism: Morrison's Beloved and the Moynihan Report." PMLA 111 (1996): 408-420.

[3] Caesar, Terry Paul. Slavery and Motherhood in Toni Morrison's Beloved. Revista de Letras, 34 (1994). 111-20.

[4] Carden, Mary P. "Models of Memory and Romance: the Dual Endings of Toni Morrison's Beloved." Twentieth Century Literature 45 (1999): 401-427.

[5] Chodorow, Nancy. "Mothering, Object-Relations, and the Female Oedipal Configuration.” Feminist Studies 4 (1978): 137-158. JSTOR Millikin U, Decatur, IL. 19 Nov. 2007 <http://www.jstor.org.>

[6] Curnow, Rick. "Trauma: A Psychoanalytic Perspective". aipsych.org. 2007. web. 22 May 2014. < http://www.aipsych.org.au/articles/aip_trauma_psychoanal ytical.pdf >

[7] Field, Robin E. "Tracing Rape: The Trauma of Slavery in Toni Morrison's Beloved." Women Writing Rape: The Blog (June 2014). <http://blogs.warwick.ac.uk/womenwriting-rape/entry/robin_e_fields $>$

[8] Grewal, Gurleen. Circles of Sorrow, Lines of Struggle: The Novels of Toni Morrison. Baton Rouge, Louisiana State University Press, 1998.

[9] Grohol, John M. "15 Common Defense Mechanisms". Psych Central. 2014. web. 23 May 2014. < http://psychcentral.com/lib/15-common-defensemechanisms $/ 0001251$ ?all $=1$

[10] Handley, William R. "The House a Ghost Built: Nommo, Allegory, and the Ethics of Reading in Toni Morrison's Beloved." Contemporary Literature 36 (1995): 676-701.

[11] Heinert, Jennifer Lee Jordan. Narrative Conventions and Race in the Novels of Toni Morrison. New York: Routledge, 2009. Print.

[12] Hilgard, Earnest E, Richard C Atkinson, and Rita L Atkinson. Introduction to Psychology. New Delhi: Oxford, 1976. Print

[13] Holden-Kirwan, Jennifer. "Looking into the self that is no self: an examination of subjectivity in Beloved." 1998. 22 June.

2014. 
<http://findarticles.com/p/articles/mi_m2838/in_n3_v32/ai _21232162>

[14] Huberty, Thomas J.. "Anxiety and Anxiety Disorders in Children: Information for Parents." National Association of School Psychologists. 2007. 23 Nov. 2007 http://www.nasponline.org

[15] Kathon, Md. Nazmus Saquib, and Kibriani, Kimana. "Projecting Mother Image: A Study

[16] Koolish, Lynda. "'To be Loved and Cry Shame': A Psychological Reading of Toni Morrison's Beloved." MELAS 26 (2001): 169-195. Academic Search Premier. EBSCO. Staley Lib., Millikin U, Decatur, IL. 14 Nov. 2007 http://epnet.com Language, Literature and Humanities. Volume III. Issue V. July 2015. ISSN 23217065.

[17] Lilian, Daise. "The Female Condition in Morrison's The Bluest Eye: from Childhood to Adulthood”. 2009.

[18] Millikin U., Decatur, IL. 14 Nov. 2007 http://epnet.com

[19] Morrison, Toni. Beloved. New York: Vintage International, 2004. Print

[20] Morrison, Toni. The Bluest Eye. Great Britain: Chatto and Windus, 1979. Print

[21] Norris-Shortle, Carole, Patricia A. Young, and May Ann Williams. "Understanding Death and Grief for Children Three and Younger." Social Work 38 (1993): 736-742. Academic Search Premier. EBSCO. Staley Lib., Millikin U, Decatur, IL. 24 Nov. 2007 http://epnet.com of Toni Morrison's Beloved and The Bluest Eye". International Journal of English

[22] Peterson, Nancy J., ed. Toni Morrison: Critical and Theoretical Approaches. Baltimore: Johns Hopkins UP, 1997. Print.

[23] "Slavery in America". history.com. A\&E Television Network. 2014. Web. 15 May 2014. < http://www.history.com/topics/black-history/slavery\# >

[24] Smith, Barbara. "Beautiful, Needed, Mysterious." Critical Essays on Toni Morrison. Boston: G.K. Hall \& Co., 1988. Print.

[25] Solomon, Barbara, ed. Critical Essays on Toni Morrison's Beloved. New York: G.K. Hall; London: Prentice Hall International, 1998.

[26] Tyson, Lois. Critical Theory Today: A User Friendly Guide. New York: Taylor \& Francis Group. 2006. Print.

[27] Vogel, John L. Thinking about Psychology. Chicago: Nelson-Hall Publishers. Print

[28] Washington, Mary Helen. "Teaching Black-Eyed Susans: An Approach to the Study of Black Women Writers." All the Women Are White, All the Blacks Are Men, but Some of Us Are Brave: Black Women's Studies. Eds. Gloria T. Hull, Patricia Bell Scott, and Barbara Smith. Old Westbury, N.Y.: New Feminist Press, 1982.

[29] Washington, Teresa N. "The Mother-Daughter Aje Relationships in Toni Morrison's Beloved." African American Review 39 (2005): 171-188. Academic Search Premier. EBSCO. Staley Lib., Millikin U, Decatur, IL. 14 June 2014 <http://epnet.com>

[30] Washington, Teresa N.. "The Mother-Daughter Àjé Relationships in Toni Morrison's Beloved." African
American Review 39 (2005): 171-188. Academic Search Premier. EBSCO. Staley Lib., Millikin U, Decatur, IL. 14 Nov. 2007 http://epnet.com 